\title{
Aprendizagem, Desempenho Escolar e Qualidade de Vida: Fatores de aproximação e de complemento
}

\section{Learning, Quality of life and School performace: Approach and complemente factors}

\author{
Queli Ghilardi Cancian ${ }^{1 *}$, Micheli Cazarolli ${ }^{1}$, Paulo Cesar Fachin ${ }^{2}$
}

\begin{abstract}
RESUMO
Inúmeros são os fatores que podem influenciar o desempenho escolar, assim, a autopercepção da criança ou adolescente quanto a condição de vida e saúde pode comprometer sua motivação frente ao aprendizado. Um fator determinante é a qualidade de vida, mais do que um conceito a qualidade de vida expressa uma condição de vida, da realidade que abrange o bem-estar total dos seres humanos, em sua condição física, mental e emocional, além da condição econômica e das interações sociais. Envoltos nesta questão, traça-se como objetivo a investigação dos fatores de risco relacionados à qualidade de vida e o desempenho escolar da criança e do adolescente. Trata-se de um estudo qualitativo de caráter descritivo, construído a partir da revisão bibliográfica de artigos, dissertações e teses publicados em bases de dados on-line. Os resultados encontrados apontaram para diferentes fatores, que podem limitar o desempenho escolar, entre eles a baixa qualidade de vida e qualidade social do aluno. De modo que, a baixa qualidade de vida apresenta-se como resultante dos diversos fatores que abrangem as condições socioculturais, ambientais, físicas, emocionais e econômicas, do aluno e dos familiares.
\end{abstract}

Palavras-chave: Amparo familiar; Desempenho escolar; Qualidade de vida; Qualidade social

\begin{abstract}
There are countless factors that can influence school performance, thus, the self-perception of children or adolescents regarding their life and health conditions can compromise their motivation towards learning. A determining factor is the quality of life, more than a concept, quality of life expresses a condition of life, the reality that encompasses the total well-being of human beings, in their physical, mental and emotional condition, besides their economic condition. And social interactions. Involved in this issue, the aim is to investigate risk factors related to the quality of life and school performance of children and adolescents. This is a qualitative descriptive study, built from a literature review of articles and dissertations published in online databases. The results found pointed to different factors that can limit school performance, including the inferior quality of life and social quality of the student. So, the low quality of life is presented
\end{abstract}

\footnotetext{
${ }^{1}$ Centro Universitário Assis Gurgacz - FAG/ Universidade Estadual do Oeste do Paraná- UNIOESTE.

*E-mail: quelicancian@gmail.com

${ }^{2}$ Centro Universitário Assis Gurgacz - FAG/ Universidade Estadual de Ponta Grossa - UEPG.
} 
because of several factors that include the socio-cultural, environmental, physical, emotional, and economic conditions of the student and their families.

Keywords: Family support; School performance; Quality of life; Social quality.

\section{INTRODUÇÃO}

Na sua amplitude, o (desempenho) se relaciona ao desenvolvimento, crescimento e formação das pessoas. Deste modo, ao longo da vida o ser humano é estimulado a desenvolver a aprendizagem, no processo escolar essa aprendizagem é medida por meio do desempenho, que significa dizer que o aluno é testado, a fim de verificar a apropriação de todo conhecimento adquirido.

Portanto, a escola se concretiza em uma organização constituída pela sociedade, com o objetivo de transmitir valores e contribuir para a formação dos alunos mediante as experiências de aprendizagem. O aluno, por sua vez, é o motivo pelo qual a escola existe e desenvolve suas ações, o mesmo, deve ser envolvido pelo processo de aprendizagem para a qual deve-se estimular a formação pessoal, ou seja, o aluno deve ser constantemente envolvido em experiências educacionais, motivadoras e estimulantes que incite o gosto de aprender. Sendo assim, a aprendizagem é o ponto de partida e também de chegada que define quantitativamente o desempenho escolar (LÜCK, 2009).

São inúmeros os fatores que podem afetar o desempenho escolar, entre eles destaca-se a qualidade de vida. Diversos autores indicam que a qualidade de vida percebida pode influenciar de forma negativa em vários aspectos da vida dos indivíduos, seja nas relações sociais, ambientais, física, metais ou emocionais (AUQUIER et al., 1997; MINAYO et al.,2000; SOARES et al., 2011; AMARO e DUMITH, 2018).

Assim, a qualidade da educação não pode ser resumida simplesmente ao rendimento escolar, já que qualidade em sua amplitude é um termo polissêmico de ampla abrangência, que parte do entendimento do próprio indivíduo sobre suas condições, estando associado ao melhoramento das condições de vida sem distinção. 
Já a qualidade social da educação implica em assegurar o melhor aprendizado do educando, pautado no princípio da eficiência e da eficácia e efetividade social (DOURADOS, 2010).

Por sua vez, cada aluno demonstra aquilo que sente, de modo que se faz necessário prestar atenção nos motivos que estimulam o desenvolvimento de determinadas ações, com o objetivo de proporcionar à criança ou ao adolescente um ambiente favorável à apropriação do conhecimento. Para tanto, a escola e as famílias devem estar unidas, para que juntas possam superar as dificuldades e proporcionar melhores condições ao educando frente ao processo de aprendizagem.

Abordar a qualidade de vida relacionada ao desempenho escolar é extremamente relevante, para que se possa compreender determinados fatores que influenciam no comportamento do educando. Embora o entendimento de qualidade de vida seja amplo, a compreensão no ambiente escolar pode colaborar na identificação de determinados fatores que afetam o desempenho do aluno.

Partindo da necessidade de compreender os fatores que influenciam o desempenho escolar, o presente trabalho busca responder os seguintes questionamentos: Quais os fatores que comprometem o desempenho escolar? A qualidade de vida e a qualidade social são fatores determinantes no desempenho escolar? O apoio e a presença da família são importantes para o processo de desenvolvimento e aprendizagem do aluno?

O objetivo da presente pesquisa é a investigação dos fatores que influenciam o desempenho escolar sobre a ótica da qualidade de vida. Assim, o estudo se justifica na necessidade de entender a influência da qualidade de vida no desempenho escolar, mediante os inúmeros fatores de risco que podem comprometer o processo de aprendizagem.

\section{METODOLOGIA}

Trata de uma pesquisa bibliográfica qualitativa, de caráter descritivo, cujo objetivo da pesquisa bibliográfica é buscar uma explicação para um problema a partir de referências teóricas publicadas em livros, teses, dissertações e artigos. Busca-se na pesquisa bibliográfica, uma revisão da literatura, a qual contribua de forma cultural e científica sobre determinado assunto, tema ou problema (CERVO; BERVIAN; DA SILVA, 2007). 
Oliveira (1999) enfatiza que o objetivo da descrição é complementar o estudo bibliográfico, de modo que possa contemplar maior precisão na frequência, relação e conexão entre os fenômenos, possibilitando, ao pesquisador, melhor compreensão do comportamento dos inúmeros fatores que influenciam em um determinado fenômeno (OLIVEIRA, 1999).

Para a construção da pesquisa, o levantamento bibliográfico não foi restrito a um período, visto que o tema desenvolvido é amplamente discutido no meio acadêmico. Para realizar a busca dos dados foram utilizados os seguintes descritores: qualidade de vida; qualidade social; desempenho escolar; influencia familiar; ambiente escolar; condições socioculturais.

Após a fase do levantamento dos estudos, criou-se um arcabouço bibliográfico, o qual primeiramente passou pela leitura exploratória ou informativa, Gil (2002, p.77), pondera que a leitura exploratória "é comparada à expedição de reconhecimento que fazem os exploradores de uma região desconhecida", esse tipo de leitura capacita o leitor selecionar os conteúdos que poderão ser utilizados em seu trabalho, assim como uma visão geral do tema.

A segunda etapa foi concretizada pela leitura seletiva, processo que se caracteriza pela leitura na íntegra do documento, a fim de encontrar subsídios que contemplem os propósitos do trabalho; a terceira etapa se concretiza pela leitura crítica ou reflexiva, momento no qual o leitor faz seleção da ideia central e das secundárias de modo que possa extrair os dados relevantes do texto; e pôr fim, a leitura interpretativa, que se consolida na análise dos dados, na seleção, na comparação e diferenciação das informações necessárias para a efetivação do presente pesquisa (CERVO; BERVIAN; SILVA, 2007).

\section{FATORES QUE INFLUENCIAM NO DESEMPENHO ESCOLAR}

Diversos são os fatores que influenciam no desempenho escolar, sejam eles positivos ou negativos. Dentre os fatores positivos, destaca-se o próprio interesse do aluno na busca pelo aprendizado, além de professores capacitados, que proporcionem aos educandos um ensino de qualidade, assim como a estrutura organizacional e administrativa da escola (JUSTI et al., 2017). 
Entre os fatores que afetam o desempenho escolar de forma negativa, podemos ressaltar o comportamento do próprio educando, por meio de conversas paralelas, brincadeiras excessivas, falta de comprometimento e (des)interesse na realização das tarefas, atitudes de afrontamento, dominância entre colegas e para com os próprios professores, entre outros.

Logo, outros fatores devem ser considerados frente ao baixo desempenho escolar, entre eles a baixa autopercepção de "qualidade de vida". Sendo a qualidade de vida um reflexo de diversos fatores que podem estar associados a doenças físicas ou psicológicas, assim como as relações pessoais e sociais, a condição socioeconômica e cultural, além do próprio ambiente escolar.

Percebe-se que um dos fatores que podem influenciar no desempenho escolar da criança e do adolescente está relacionado às condições de saúde. Para compreender melhor a concepção de saúde adotamos a definição de saúde orientada pela $8^{\circ}$ Conferência Nacional de Saúde em 1986, mais tarde foi incorporada à Constituição Federal de 1988, que vem considera que a saúde como:

[...] resultante das condições de alimentação, habitação, educação, renda, meio ambiente, trabalho, transporte, emprego, lazer, liberdade, acesso e posse da terra e acesso a serviços de saúde. É, assim, antes de tudo, o resultado das formas de organização social da produção, as quais podem gerar grandes desigualdades nos níveis de vida; a saúde não é um conceito abstrato. Definese no contexto histórico de determinada sociedade e num dado momento de seu desenvolvimento, devendo ser conquistada pela população em suas lutas cotidianas ( $8^{\circ}$ CONFERÊNCIA NACIONAL DE SAÚDE, 1986, p. 4).

Compreendendo que as condições de saúde estão envoltas sobre diversas dimensões que podem comprometer não somente as condições de saúde, mas a qualidade de vida e todas as relações do sujeito, seja na vida pessoal, profissional ou escolar.

Assim, a condição socioeconômica e cultural (das famílias e dos alunos), podem influenciar de forma significativa na aprendizagem escolar. Partindo dessa premissa os autores Dourados; Oliveira; Souza, afirmam que:

[...] O nível de renda, o acesso a bens culturais e tecnológicos, como a Internet, a escolarização dos pais, os hábitos de leitura dos pais, o ambiente familiar, a participação dos pais na vida escolar do aluno, a imagem de sucesso ou fracasso projetada no estudante, as atividades extracurriculares, entre outras, interferem significativamente no desempenho escolar e no sucesso dos alunos (DOURADOS; OLIVEIRA; SOUZA, 2007 p. 14).

A baixa autoestima, a desmotivação ou falta de interesse do educando, é sinal de que algo não está bem, a "criança ou adolescente", assim como qualquer ser humano 
adulto está exposto a diversas situações que podem abalar a condição emocional, comprometendo de forma significativa sua vida e o desempenho na escola.

\subsection{A destaque da família no desempenho escolar}

Leontiev (1978) destaca que o homem é produto da própria cultura, que faz parte da capacidade de aprender e transformar o meio em que vive. Deste modo, torna-se capaz de acumular conhecimento e transmiti-lo de geração a geração, por meio da educação. $O$ autor destaca que a interação social é o que possibilita os indivíduos a desenvolverem aptidões de acordo com o meio o qual se encontram inseridos.

A escola assim como a família, surge como uma instituição necessária para estimular o processo evolutivo do homem, agindo como agentes inibidores ou propulsores do seu desenvolvimento intelectual e social. A escola se estabelece em diversificadas atividades formais e informais de aprendizagem em um contexto ao qual a criança investe seu tempo em busca de conhecimento. Na escola as necessidades cognitivas, psicológicas, sociais e culturais da criança são realizadas de modo mais estruturado e pedagógico do que as atividades desenvolvidas no ambiente familiar. Portanto, o ambiente familiar não é o único acesso da criança às oportunidades de desenvolvimento e ampliação da aprendizagem (POLONIA e DESSEN, 2005).

Vygotsky (2005) aponta que o aprendizado provém primeiramente de um círculo social e cultural em que os indivíduos se encontram inseridos, não advindo apenas dos ambientes escolares. Dentro desta concepção, o autor destaca que cada criança aprende de uma forma diferente, umas com maior apropriação de conhecimento do que outras, característica do desenvolvimento afetivo da criança.

A escola nada mais é do que um espaço social, que divide com as famílias a obrigação educacional da criança. Pais e escola trabalham em conjunto, colaborando um com o outro na construção cultural, social do aluno frente ao aprendizado e a sociedade (ALMEIDA, 2014).

O primeiro grupo social ao qual o aluno tem acesso é a própria família, buscando, por meio das interações, o aprendizado e toma como referência os valores culturais emocionais extraídos das experiências proporcionadas e vivenciadas por seu grupo familiar. Assim, os pais são responsáveis por mediar junto a escola o desenvolvimento e o aprendizagem do aluno, assim como sua inserção na sociedade. A ausência dos pais, o 
vínculo familiar ruim, pode comprometer a autoestima e a motivação do aluno, ocasionando distúrbios e prejudicando a aprendizagem (PARO, 1997).

A presença dos pais na vida escolar da "criança ou adolescente" possui um papel fundamental no desempenho do aluno, os autores Justi et al., destacam que:

\begin{abstract}
A escola, por sua maior aproximação às famílias, constitui-se em instituição social importante na busca de mecanismos que favoreçam um trabalho avançado, no sentido de uma atuação que mobilize os integrantes tanto da escola, quanto da família, em direção a uma maior capacidade de dar respostas aos desafios que se impõem a essa sociedade (JUSTI et al., 2017, p. 23823).
\end{abstract}

A escola, juntamente com as famílias, busca capacitar os alunos para serem cidadãos atuantes, capazes de se relacionar de forma positiva tanto no ambiente escolar como na sociedade.

O bom desenvolvimento escolar do aluno pode ser afetado por alguns fatores de risco, que estão relacionados a momentos e a condições negativas vividas pelo aluno e/ou familiares, expondo os educandos a maiores possibilidades de apresentarem problemas de caráter físico, social ou emocional (BRONFENBRENNER, 1996).

Os pais possuem um importante papel frente a escolarização dos filhos, alguns aspectos podem implicar no desempenho da criança. As autoras Polonia e Dessen ressaltam a presença da família na vida escolar da criança:

\footnotetext{
A família como impulsionadora da produtividade escolar e do aproveitamento acadêmico e o distanciamento da família, podendo provocar o desinteresse escolar e a desvalorização da educação, especialmente nas classes menos favorecidas (POLIANA e DESSEN, 2005 p. 304).
}

A presença da família proporciona segurança à criança frente às dificuldades encontradas no ambiente escolar. É importante que a criança, frente as suas vulnerabilidades, receba o apoio dos pais, pois a ausência dos mesmos pode ocasionar desmotivação, prejudicando o desempenho escolar da criança e/ou adolescente.

\title{
3. QUALIDADE DE VIDA, MAIS DO UM CONCEITO, UMA DETERMINANTE NO DESEMPENHO ESCOLAR
}

O desempenho da criança na fase escolar pode ser afetado por diversos fatores, os quais podem ser superados de forma rápida e sem intervenção ou, ainda, prolongar-se gerando inúmeros prejuízos no desenvolvimento da própria criança, além de prejudicar os demais colegas. 
A baixa percepção de qualidade de vida da criança tem sido um dos fatores influenciadores no baixo desempenho escolar, mas o que é qualidade de vida afinal de contas?

O termo qualidade de vida define o nível das condições essenciais e complementares para a vida do ser humano. Esta condição abrange o bem-estar físico, mental, psicológico e emocional, assim como os relacionamentos sociais, entre familiares e amigos, a própria saúde, a educação e outros fatores que possam afetar a vida humana (AMARO e DUMITH, 2018).

Considerando os múltiplos aspectos da vida humana, a Organização Mundial da Saúde (OMS) define o conceito de qualidade de vida, como "a autopercepção do indivíduo quanto à sua posição na vida, de acordo com a cultura e o sistema de valores nos quais ele se encontra e em relação aos seus objetivos, expectativas, padrões e preocupações" (The WHOQOL Group, 1995, p. 1405). tal conceito descrito pelo grupo WHOQOL, considera a natureza subjetiva do sujeito de acordo com seu contexto ambiental, cultural e social

Soares (2011), destaca que o termo qualidade de vida deve ser utilizado com rigor, ampliando em seu significado global por meio da identificação e ampliação dos conceitos de forma crítica e reflexiva, evitando o seu uso apenas como pertença de marca, positiva. Portanto, a qualidade de vida deveria contemplar o bem estar total do ser humano, sem limitações ou privações inerentes a condição social, racial ou religiosa.

Uma condição importante é não confundir qualidade de vida com padrão de vida, a qual se refere propriamente a condição financeira ou econômica do indivíduo. De modo que a qualidade de vida não está associada quantitativamente ao crescimento material, mas sim aos valores qualitativos da condição de vida dos homens.

A qualidade de vida não se restringe apenas a ideia de satisfação material, estando relacionada aos valores subjetivos do próprio sujeito, de caráter não material, concretizando-se pela inserção social, a sensação de bem-estar físico e mental, de felicidade e liberdade entre outras. (AUQUIER et al., 1997).

Portanto, qualidade de vida e saúde são termos diretamente relacionados, uma vez que a boa saúde colabora para uma melhor qualidade de vida. Nesse sentido, a Organização Mundial da Saúde (OMS) define o termo saúde como "um completo estado de bem estar físico, mental e social, que consiste não apenas em ausência de doença ou enfermidade", mas o completo bem estar total (SILVA, 2006, p.28). 
Portanto, assegurar o desenvolvimento saudável das crianças e dos adolescentes é dever do estado, desenvolvendo e concretizando políticas públicas voltadas ao cuidado e ao atendimento dos indivíduos. Nesse sentido, o artigo $7^{\circ}$ da lei $n^{\circ} 8.069 / 90$ do Estatuto da Criança e do Adolescente (ECA), orienta que, "a criança e o adolescente têm direito à proteção, à vida e à saúde, mediante a efetivação de políticas sociais públicas que permitam o nascimento e o desenvolvimento sadio e harmonioso, em condições dignas de existência" (BRASIL, 2021, n.p.).

Em consonância com o artigo da lei, constata-se que os direitos fundamentais à vida e à saúde que deveriam contemplar a dignidade e o bem-estar de todos, inúmeras vezes falha, considerando assim as desigualdades sociais e seus reflexos na qualidade de vida e social dos sujeitos. Nessa direção, observa-se que o baixo interesse e desempenho do aluno está intrinsecamente ligado às condições de vida e ao meio social ao qual o mesmo se encontra inserido.

Outros fatores podem afetar o desempenho escolar e, nesse sentido, voltamos nossos olhares às mudanças do século XX, marcado pela globalização, pelas inúmeras transformações tecnológicas e sociais do mundo contemporâneo, ocasionando diversas transformações estruturais, econômicas, sociais e políticas, alterando o comportamento e o estilo de vida dos seres humanos (SILVA, 2006; PRIESS, 2012).

Junto com a globalização vieram as enfermidades, ocasionadas pelos maus hábitos e o estilo de vida adotado. $\mathrm{O}$ excesso de produtos industrializados e a falta de atividade física, bem como o acesso e excesso das multitecnologias (jogos e interações) que, por vezes, têm colaborado para o desenvolvimento de inúmeras doenças, afetando toda a população, inclusive crianças (SOUZA, 2001).

Os excessos estimulados pela globalização têm influenciado na baixa autoestima, na socialização e interação, além de colaborar no desenvolvimento de doenças físicas, psicológicas e emocionais, refletindo na baixa qualidade de vida do sujeito. Nota-se que o adoecimento, além de promover a queda na qualidade de vida, reflete de forma negativa na aprendizagem e no desempenho escolar.

\subsection{A influência da qualidade social, na qualidade de vida do aluno}

A qualidade social da educação está envolvida em um processo pedagógico que implica assegurar o melhor aprendizado do educando, pautado pela eficiência, eficácia e 
efetividade social. Tão $\operatorname{logo}$, o conceito de qualidade não pode ser resumido em rendimento escolar, mas sim em busca constante de medidas e ações que proporcionem melhores resultados na aprendizagem (DOURADOS, 2010).

O termo "qualidade" é complexo e polissêmico, de enorme abrangência, no entendimento de Gadotti,

\begin{abstract}
Qualidade significa melhorar a vida das pessoas, de todas as pessoas. Na educação, a qualidade está ligada diretamente ao bem-viver de todas as nossas comunidades, a partir da comunidade escolar. A qualidade na educação não pode ser boa se a qualidade do professor, do aluno, da comunidade é ruim. Não podemos separar a qualidade da educação da qualidade como um todo ... (GADOTTI, 2010, p. 07).
\end{abstract}

De acordo com Dourados (2010), a qualidade social voltada para a educação compreende um conjunto de fatores intra e extraescolares, os quais se referem às condições de vida do aluno e seus familiares no contexto social, cultural e econômico, além da própria escola, que abrange a estrutura organizacional, professores, diretores, projetos pedagógicos, recursos, ambiente escolar e as interações sociais.

De modo que a qualidade social está ligada às dimensões socioeconômicas e culturais de uma sociedade, uma vez que a qualidade da escola também está associada à ideia de não poder perder de vista o nível do espaço social.

Os autores Dourados; Oliveira; Souza, fazem uma compressão mais aprofundada da qualidade da escola diante das dimensões socioeconômica e culturais,

[...] uma vez que o ato educativo escolar se dá em um contexto de posições e disposições no espaço social (em conformidade com o acúmulo de capital econômico, social e cultural dos sujeitos-usuários da escola), de heterogeneidade e pluralidade sociocultural, de problemas sociais refletidos na escola, tais como: fracasso escolar, desvalorização social dos segmentos menos favorecidos, incluindo a autoestima dos alunos, etc. (DOURADOS; OLIVEIRA; SOUZA, 2007, p.14).

Logo, a qualidade social abordada no contexto escolar possui ampla relação com a qualidade de vida dos alunos e seus familiares, de modo que a qualidade social marcada pela desigualdade socioeconômica e cultural afeta diretamente a realidade e a qualidade de vida do aluno, implicando no desempenho do escolar.

Na compreensão da educação como uma prática social, que ocorre em diversos momentos da produção da vida social do ser humano, destaca-se o papel da escola no processo formativo e nos variados níveis e modalidades educativas, destacando-se a importância das políticas sociais educativas no enfrentamento das questões extraescolar, que afetam o processo educativo, interferindo nas finalidades educacionais e na 
orientação do processo ensino/aprendizagem (DOURADOS; OLIVEIRA; SOUZA, 2007).

A baixa condição socioeconômica ou baixa 'qualidade social' da criança ou adolescente, interfere na autopercepção de qualidade de vida, ocasionando desmotivação e diminuição das capacidades de enfrentamento. A baixa qualidade de vida se reflete no ambiente escolar relacionada aos fatores de risco.

Bronfenbrenner, (1996) descreve que as condições de risco estão associadas a momentos e a condições enfrentadas pelo aluno, podendo ocasionar problemas de caráter físico, social ou emocional. Tais problemas interferem tanto na vida pessoal como na vida escolar do aluno, comprometendo o desempenho escolar e a aprendizagem.

Assim sendo, a qualidade da educação está envolta aos paradigmas da qualidade social, a partir dessa abordagem Gadotti faz uma reflexão:

\footnotetext{
Falar em qualidade social da educação é falar de uma nova qualidade, onde se acentua o aspecto social, cultural e ambiental da educação, em que se valoriza não só o conhecimento simbólico, mas também o sensível e o técnico (GADOTTI, 2010, p. 05).
}

A escola exerce um papel específico na construção do aprendizado e, faz parte deste processo, a incorporação das diferenças, o combate às desigualdades. Para Gadotti (2010), a qualidade sociocultural e socioambiental significa que se deve respeitar as diversidades, sem distinção ou opressão.

\section{CONSIDERAÇÕES FINAIS}

Há muitas discussões e reflexões a respeito da qualidade do ensino frente aos resultados de diversos tipos de avaliações, mas o desempenho propriamente dito é apenas uma fração dessa totalidade que envolve o ambiente escolar. De modo, que o desempenho escolar é afetado por diversos fatores, de ordem (intrínseca ou extrínseca) do aluno, sendo ocasionado por causas ambientais, físicas, psicológicas e socioeconômicas.

Somos reflexo daquilo que sentimos. A criança e o adolescente se expressam por meio de atitudes e comportamentos que podem influenciar no desempenho escolar. $\mathrm{O}$ aluno desmotivado, com baixa autoestima, com baixa perspectiva de vida, não consegue encontrar motivação para a realização das atividades escolares tendo, como resultado, o baixo desempenho. 
Logo, a baixa autopercepção do aluno sobre a qualidade de vida, é um reflexo do momento e das condições enfrentadas, em resposta a problemas de caráter físico, ambiental, social, emocional ou econômico.

A responsabilidade do baixo desempenho não pode ser atribuída unicamente à condição social e econômica, embora esses fatores apresentam forte influência na vida pessoal, social e escolar do aluno. Assim sendo, um conjunto de fatores devem ser levados em consideração, a fim de identificar as causas do baixo desempenho escolar.

Doenças físicas, assim como psicológicas, devem ser consideradas na avaliação do desempenho escolar, de modo que a criança com problemas de saúde crônica pode se sentir limitada, prejudicando seu desempenho. Diversos fatores podem influenciar na condição psicológica da criança, estimulando precocemente o aparecimento de doenças, tais como estresse ou depressão, que automaticamente ocasionam declínio na qualidade de vida, assim como no desempenho escolar do educando.

Podemos considerar que somos produto do meio cultural em que nos encontramos inseridos e, deste modo, faz-se importante a presença da família no contexto escolar, sendo primordial que os pais estejam presentes na vida escolar dos filhos, pois o apoio da família promove segurança e ajuda a criança a superar as dificuldades de aprendizagem.

As questões socioeconômicas são, em parte, responsáveis pela baixa qualidade de vida e a baixa condição financeira é um limitador nas condições básicas de vida em relação à saúde, alimentação, lazer, locomoção, vestimenta, comunicação, informação, educação entre outros. Todos esses fatores ocasionam baixa qualidade de vida, ocasionando dificuldades no processo aprendizagem, concretizando-se no baixo desempenho escolar.

Atenção! Cada educando demonstra aquilo que sente. Suas ações e motivações são reflexos da sua realidade e visão de mundo. Cabe à escola, posicionar-se como agente social transformador, identificando e buscando melhorar as possibilidades de aprendizagem desse estudante.

\section{REFERÊNCIAS}

ALMEIDA, E. B. de. A relação entre pais e escola: a influência da família no desempenho escolar do aluno. Campinas, SP:[sn], 2014. Disponível em: www.bibliotecadigital.unicamp.br/document/?down=000943944 Acesso em: 08 ago. 2021. 
AMARO, J. M. R. S.; DUMITH, S. C. Sonolência diurna excessiva e qualidade de vida relacionada à saúde dos professores universitários. J Bras Psiquiatr, v. 67, n. 2, p. 94$100,2018$.

AUQUIER P, SIMEONI MC, MENDIZABAL H. Approches théoriques et méthodologiques de la qualité de vie liée à la santé. Revue Prevenir, v. 33, n. 1, p. 7786, 1997.

BRASIL. Lei no 8.069, 13 de julho de 1990. Dispõe do Estatuto da Criança e do Adolescente e outras providências. Disponível em:

http://www.planalto.gov.br/ccivil_03/leis/18069.htm\#: :text=Art.\%207\%C2\%BA\%20A $\% 20$ crian\%C3\%A7a\%20e,em\%20condi\%C3\%A7\%C3\%B5es\%20dignas\%20de\%20exi st\%C3\%AAncia. Acesso em: 29 jun. 2021.

BRONFENBRENNER, U. A ecologia do desenvolvimento humano: experimentos naturais e planejados. Porto Alegre: Artes Médicas, 1996.

CERVO, A. L.; BERVIAN, P. A.; SILVA, R. da. Metodologia científica. 6. ed. São Paulo: Pearson Pretice Hall, 2007.

CONFERÊNCIA NACIONAL DE SAÚDE. $8^{\circ}$ conferência Nacional de saúde, relatório final. Ministério da Saúde 17-21 de março de 1986. Disponível em:

https://bvsms.saude.gov.br/bvs/publicacoes/8_conferencia_nacional_saude_relatorio_fi nal.pdf. Acesso em: 08 fev. 2021.

DOURADO, L. F.; OLIVEIRA, J. F. de; SANTOS, C. de A. A qualidade da educação: conceitos e definições. Brasília, DF: Inep, 2007.

GADOTTI, M. Qualidade na educação: uma nova abordagem. 2010. Disponível em: https://www.acervo.paulofreire.org:8080/jspui/bitstream/7891/3086/1/FPF_PTPF_12_0 84.pdf. Acesso: 22 ago.2019

GIL, A. C. Como elaborar projetos de pesquisa. 4. ed. São Paulo: Atlas, 2002.

JUSTI, J.; FREITAS, F. M. P. R.; DE OLIVEIRA, H. X. VASCONCELLOS C. F. C; Fatores que influenciam o desempenho escolar de adolescentes de uma instituição pública do município de rio verde, GO. 2017. Disponível em:

https://educere.bruc.com.br/arquivo/pdf2017/23049_11679.pdf. Acesso em: 05 ago. 2021.

LEONTIEV, A. O desenvolvimento do psiquismo. São Paulo: Moraes, 1978.

LÜCK, H. Dimensões da gestão escolar e suas competências. Curitiba: Editora Positivo, 2009.

MINAYO, M. C. de S.; HARTZ, Z. M.de A.; BUSS, P. M. Qualidade de vida e saúde: um debate necessário. Ciência \& saúde coletiva, v. 5, p. 7-18, 2000. 
OLIVEIRA, L. S. Tratado de metodologia científica projetos de pesquisa, tgi, tcc, monografias, dissertações e teses. 2. ed. São Paulo: Pioneira Thompson Learning, 1999.

POLONIA, A. da C.; DESSEN, M. A. Em busca de uma compreensão das relações entre família e escola. 2005. Disponível em:

https://www.scielo.br/pdf/pee/v9n2/v9n2a12 Acesso em: 13 ago. 2021.

PARO, V. H. Qualidade do ensino: a contribuição dos pais. São Paulo: Xamã, 1997.

PRIESS, F. G. Características do estilo de vida e da qualidade de vida dos

professores universitários de instituições privadas de Foz Iguaçu e região. 2012.

Disponível em: https://acervodigital.ufpr.br/handle/1884/26495. Acesso em: 08 jul.

2021.

SILVA, R. Características do estilo de vida e da qualidade de vida de professores do ensino superior público em Educação Física. 2006. Disponível em:

https://repositorio.ufsc.br/handle/123456789/103127. Acesso em: 08 jul. 2021.

SOARES, A. H. R. et al. Qualidade de vida de crianças e adolescentes: uma revisão bibliográfica. Ciência \& Saúde Coletiva, v. 16, p. 3197-3206, 2011.

SOUZA, S. D. de et al. Qualidade de vida de professores universitários em fase de mestrado. 2001. Disponível em: https://repositorio.ufsc.br/handle/123456789/81628. Acesso em: 08 jul. 2021.

The WHOQOL Group. The World Health Organization quality of life assessment (WHOQOL): position paper from the World Health Organization. Soc Sci Med 1995; 41:1403-10.

VYGOTSKY, L. Aprendizagem e desenvolvimento intelectual na idade escolar. In: LEONTIEV, Alexei Nikolaevich et al. Psicologia e Pedagogia: as bases psicológicas da aprendizagem e do desenvolvimento. 3. ed. São Paulo: Editora Centauro, 2005.

\section{Recebido em: 01/09/2021}

Aprovado em: 12/09/2021

Publicado em: 16/09/2021 